\section{DE RODALQUILAR A RECANATI: FRAGMENTOS DE UN UNIVERSO INEVITABLEMENTE AMOROSO}

\author{
Isabel Prieto Palomo \\ Traductora y escritora
}

\begin{abstract}
The article is an analysis on the translation and the study of Leopardi carried out by Carmen de Burgos; the disparate psychology of both and the Recanati poet is discussed: Leopardi's vital pessimism versus the authoress vitality who applied to the Italian poet the same trend the European Romanticism felt the duty of the existence with
\end{abstract}

KEY WORDS: Carmen de Burgos; Colombine; Leopardi; Almeria; Rodalquilar; Recanati; European Romanticism

\section{FROM RODALQUILAR TO RECANATI: FRAGMENTS OF A UNAVOIDABLE LOVING UNIVERSE}

RESUMEN: Se comenta la traducción y estudio de Leopardi por parte de Carmen de Burgos, y se plantea la disparidad de la psicología de Colombine y la del poeta de Recanati: un pesimismo vital por parte de Leopardi y la vitalidad de la escritora, que aplica al poeta italiano la tónica con que el Romanticismo europeo sintió el deber de la existencia.

PALABRAS CLAVE: Carmen de Burgos; Colombine; Leopardi; Almeria; Rodalquilar; Recanati; Romanticismo europeo.

A Julio, barrockero y gaudente, por tantas sensaciones indefinibles que, al final, eran y son tan ciertas como la belleza de los valles toscanos y las playas de Cabo de Gata.

Ante todo, debo justificarme no ya por mi presencia en este volumen, sino por el carácter de lo que voy a escribir. No soy una filóloga "practicante", ni una investigadora o una profesora de Literatura. Soy, simplemente, una cuentista cincuentona, a la que leer y escribir le ha gustado siempre muchísimo, prácticamente desde que aprendió a hacerlo, a los cinco años, y a la que cuando le preguntan a qué se dedica, es decir, cómo se gana más o menos la vida, suele contestar: "A las chapuzas intelectuales: edición, corrección de estilo, traducciones...". No sonará, quizá, muy bien, pero cómo explico, si no, la época en la que leía el Hola buscando ideas y posibles autores, o que uno de los libros que he traducido sea un burlón manual de autoayuda titulado Cómo dejar de hacerse pajas mentales. (Por no extenderme sobre cierta ocasión en la que un autor, por teléfono, se presentó a sí mismo de esta forma: "Soy Fulano de Tal, el del falo portentoso". Tenía su explicación, claro, El falo portentoso era el título de su último libro, pero de todas formas -y aunque el hombre ya no debía tenerlas todas consigo, dado que me insinuó que quería pasarse a la novela histórica-, sigue siendo el caso de exceso de autoestima más impresionante que he oído nunca. También un buen resumen de en qué ha consistido, muchas veces, mi vida laboral y para qué público suelo trabajar. Eso sí, con todo respeto. A diferencia de algunos compañeros, no me parece que el español medio sea un "bestia" porque no sabe quiénes fueron Horacio o Baudelaire $y$, por lo tanto, no se compre sus ediciones. Es más, los lectores para los que edité libros de humor o el electrizante reportaje sobre asesinos españoles Así son, asi matan me caían francamente bien.)

Lo que sigue van a ser, pues, unas meras impresiones de lectora-chapucera intelectual, sin más apoyo "erudito" -una palabra detestable, por cierto- que mis recuerdos, mis intuiciones y, por supuesto, mis brame. Es decir, esos "intensos deseos" o "anhelos" o "ansias" -a veces, si así lo indica el contexto, también "codicias", "avaricias"- sin los cuales, según señalaba Cesare Greppi en un bellísimo libro, I testimoni, ningún ser humano sería capaz de interpretar la realidad y pasar del estupor inicial que sentimos ante sus fragmentos: un paisaje especialmente bello; el horror de que te deje el hombre al que amas; el gusto de reírse a carcajadas; un poema cuyo autor, misteriosamente, parece 
saberlo todo de ti; el placer de la memoria cuando regresas a aquel paisaje especialmente bello.

Y así, sin más, comienzo por el que fue mi "primer estupor" cuando leí lo que escribió Carmen de Burgos, Colombine, acerca de Giacomo Leopardi: ¿por qué a una animosa señora almeriense, tirando a guapa, le gustó tantísimo la obra de un conde toscano muy feo, muy culto y sempiternamente quejumbroso? ¿Qué pudo acercar a aquella mujer que jamás dejó de ser la adolescente que cabalgaba, libre y felicísimamente, por los campos de Rodalquilar, a un hombre que consumió su adolescencia encerrado en su casa natal de Recanati, estudiando y traduciendo griego clásico mientras miraba -sólo miraba- cómo eran otros los que salian de sus casas, hacian amigos, se enamoraban, vivían, en una palabra, y que, como única respuesta a su timidez ante la vida, se comparó a un pajarillo solitario que sólo sabe desperdiciar la primavera? ¿Qué le atrajo de un autor romántico que, a diferencia de tantos de sus contemporáneos, jamás se comprometió con riesgo alguno y cuya vida, vista desde fuera, parece calcada de una obra de Chejov? ¿Por qué entendió tan bien qué amó realmente ese personaje casi chejoviano en la pobre criadita a la que dedicó el canto XXI, "A Silvia"?

Hay una primera -y obvia- explicación: el feo y quejumbroso conde fue un prosista interesante y un poeta excepcional. En España, conocerlo sigue siendo una rareza reservada, casi, a tres grupos de personas -los italianistas y demás filólogos cercanos al italianismo; los alumnos y ex alumnos del Liceo Italiano (es mi caso); los poetas-, pero hay una escena en la película Amarcord que ilustra perfectamente el lugar que ocupa Leopardi en otras partes del mundo o la cultura. Un vejete se dirige a una supuesta turista extranjera y le pregunta, coquetonamente: "¿No sabe usted quién es Leopardi? Ah...". Acto seguido, levanta la palma de la mano todo lo que puede e indica: "Dante Alighieri"; luego baja la mano unos pocos centímetros y vuelve a indicar: "Leopardi". Carmen de Burgos fue, como primera respuesta, una turista extranjera a la que, simplemente, la convenció del todo el coquetón vejete. Leopardi formaba, con Foscolo y Manzoni, un terceto casi tan "excelso" como ese Dante-Petrarca-Boccaccio sin el que la literatura europea hubiese sido otra cosa. ( $Y$ no sólo la literatura: el Canzoniere de Petrarca educó sentimentalmente a generaciones de europeos, incluidos los cortesanos adictos a los burdeles. El gran Aretino se rie maravillosamente de ellos para defender, de paso, la posibilidad de otra literatura. Pero eso es otra historia.)

El "problema", por así decirlo, es que en Carmen de Burgos no late, sólo, la obligada admiración de todo buen turista literario hacia un reconocido poeta. ¿Por qué se palpa, casi, en lo que escribió sobre él, una auténtica identificación afectiva con la figura de Giacomo Leopardi? Y me explico: la obra de Leopardi es, en gran medida, una meditación continua sobre el dolor en la que está implícita la aceptación del mismo como forma, casi, de conocimiento. El dolor es la esencia de la naturaleza humana y de la propia naturaleza. Rechazarlo, combatirlo es negarse a uno mismo, desconocerse, y conducir tu vida de una forma básicamente falsa.

Así lo leyeron muchos de sus contemporáneos (Schopenhauer recuerda una vez en la que coincidieron en Venecia "los tres grandes pesimistas": Byron, Leopardi, y él). Asi entusiasmó a Unamuno (según parece, compartía la admiración de Leopardi hacia la retama, ese humilde arbusto que, a diferencia de los hombres, asume valientemente su mortalidad, sin recurrir a engañosos consuelos como la existencia de Dios o la posibilidad del progreso humano). Y así, curiosamente, se le sigue leyendo en un nivel, digamos, popular: en Facebook, Leopardi cuenta con una página en la que, tras superar el "estupor inicial" de que el conde Giacomo Leopardi te haya aceptado como amiga, puede comprobarse, leyendo las entradas de sus otras "amigas", que, al margen de las decisiones de la crítica literaria y la filología, Leopardi sigue siendo, ante todo, el gran poeta que hace que te sientas comprendida cuando además de estar tristísima, lo estás sin remedio y porque sí. (Empleo el femenino no por empatía con la peculiar ministra Aído: es que la mayoría de las entradas de la página son de mujeres. Los hombres tienden más a colgar alegres fotos de sus visitas a Recanati, y punto. Me parece curioso.)

Y vuelvo a mi estupor inicial: ¿por qué esa identificación de la casi imbatible Colombine con un profesional del pesimismo? Problemas y desgracias no le faltaron, desde luego, pero si hay algo que recorre toda la biografia de Carmen de Burgos, casi hasta su mismo final, es, justo, su rebeldía, a veces envidiablemente heroica, frente al dolor.

Repasemos un poco: Carmen de Burgos nace en Almería en 1867, es decir -anticipo una de mis mayores admiraciones 
hacia el personaje-, en un mundo en el que, de aventurar alguien que iba a producirse la famosa revolución feminista de los años 70 -ésa por la que empezó a dejarse de considerar que "puta" era toda mujer que tenía relaciones sexuales con un hombre que no fuera su marido-, lo hubiesen mirado exactamente igual que si dijese que, al final, ni estación de ferrocarril presuntamente diseñada por Eiffel, ni Alcazaba presuntamente construida por Abderramán III, ni uva de Dalías, naranjas de Gádor y Rioja y nenúfares de Villaespesa: lo que iba a situar a Almería en el mapa del sueño, las brame y la cultura iban a ser las playas únicas de Cabo de Gata, un monigote pintado en unas cuevas -convenientemente rediseñado por una panda de excéntricos que le ponían a sus gatos nombres como Tiziano y aseguraban que La Chanca era un escenario cubista-, y un aparente oxímoron: el western europeo (ialguien sabria entonces "eso del western qué es lo que era"?). 0 sea, como a un loco peligroso o a un idiota: lo sé porque parte de mi infancia y mi adolescencia transcurrieron en una Almería que se parecía mucho más a la de Carmen de Burgos que a la actual.

En ese mundo, perfectamente ajeno, entre tantas cosas insospechables, a que parte de su destino estético lo iban a cincelar un monigote de dudosa tilde (¿indalo?, ¿índalo?) y las bandas sonoras de un tal Ennio Morricone, Carmen de Burgos creció, se casó muy joven con un guaperas que resultó ser un impresentable (ella lo definió como "esclavo de sus vicios"), lo plantó, y, lejos de asumir el destino que, en el mundo en el transcurrió mi adolescencia, era todavía el único reservado a una mujer "decente" que tenía la desgracia de "casarse mal", es decir, lejos de vestirse de luto eterno por su sexualidad y pasar a engrosar el grupo de las mujeres "amargadas", pero intachables, se fue a Madrid, dispuesta a ganarse la vida como escritora, adoptó el pseudónimo de Colombine (elección, por cierto, con la que demostró que no se había leído jamás un canovaccio de la Commedia dell'Arte, pero bueno, tampoco Lorca se molestó mucho en enterarse de qué fue eso exactamente), tuvo, quizá, sus escarceos con Blasco lbáñez y, sobre todo, formó con un hombre mucho más joven que ella lo que hoy llamaríamos una pareja de hecho. Insisto: recuerdo demasiado las charlas con las que, justo en los años 70, aún pretendian educarnos, sexual y sentimentalmente, a las adolescentes, como para no caer rendida de admiración ante el valor de Colombine: iijY eso lo hizo una niña bien almeriense que nació casi cuarenta años antes que mi abuela!!!
Pero no sólo: Carmen de Burgos hizo bandera ética de lo que podría haberse quedado en una mera circunstancia personal y defendió a capa y espada el divorcio, la educación de la mujer, la igualdad de derechos entre el padre y la madre... Incluso ante un horror que, hoy en dia, hubiese arrumbado a cualquiera como fue la muerte de varios de sus hijos, cuando aún eran apenas bebés, reaccionó promoviendo campañas para prevenir la mortalidad infantil que, sobre todo en Almería, era altísima. Cierto, la muerte de un niño pequeño no era entonces la trágica excepción que es ahora (siempre me ha impresionado muchísimo que, en Ana Karenina, la cuñada de Ana, Dolly, recuerde la muerte de uno de sus niños como una desgracia más inherente a la condición femenina: las molestias del embarazo, los dolores del parto, los pezones que se agrietan durante la lactancia, las noches en vela porque el niño no para de llorar y... la muerte de la criatura. Descubrir, a través de los Diarios de Tolstoi y de su mujer, que la muerte de un crío que no había cumplido aún los dos años podía vivirse realmente así, y por los propios padres, me impresionó aún más, obviamente) pero, con todo, hace falta ser valiente -y optimista- para, en vez de limitarse a intentar pasar página, extraer de ahí la fuerza desde la que combatir la existencia de ese dolor rotundamente insuperable.

En una palabra, Carmen de Burgos fue una mujer que reaccionó siempre ante el sufrimiento -el suyo personal $y$, desde ahí, el de toda una sociedad- no sólo intentando ser feliz, sino dejándose la piel en que el mundo pudiera serlo, con esa constancia irreductible que sólo tienen los optimistas viscerales, los que viven y aman y se esfuerzan como si, de verdad, hasta su propia vida pudiera ser mejor al día siguiente. (Su cercano Giacomo Leopardi, en cambio, empleó buena parte de su talento en demostrar que esos optimistas incurables no sólo son unos ilusos, sino que se acercan peligrosamente a la categoría de pobres idiotas. Ejemplo: hace falta ser entre crédulo y memo para pensar que, sólo porque sea 31 de diciembre, a partir del 1 de enero se va a ser, por fin, feliz.)

Cierto, dejando a un lado ciertos aspectos de la rancia burguesía almeriense, Carmen de Burgos vivió en un mundo que facilitaba mucho la creencia en que todo podía -y debía, el optimismo cobró casi un matiz ético entre algunos de sus contemporáneos- ser mejor. Hace poco, un amigo intimo, A. Roth Venier, hablándome, precisamente, de sus antepasados almerienses, me decía que hay momentos de

ARBOR CLXXXVI EXTRA JUNIO 2010 151-156 ISSN: 0210-1963

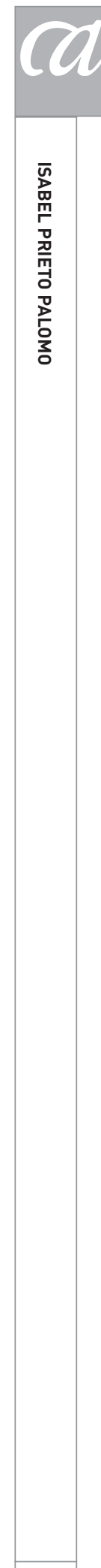


la Historia en los que parece que todo un colectivo vive como si, al paso siguiente, fuese a rozar con sus propios dedos la fuente de la eterna juventud. No cierra los ojos ante el sufrimiento, todo lo contrario, lo observa y analiza con plena lucidez, pero lo hace desde el convencido optimismo de que es remediable. Y algo remediable, no sólo duele mucho menos, sino que puede ser un acicate formidable para seguir ejerciendo el optimismo. A. Roth Venier me lo comentaba, concretamente, con respecto a uno de sus tatarabuelos, Ubaldo Venier, quien, después de asistir a la primera exhibición pública de luz eléctrica en Almería, se hizo accionista de la "fábrica de luz" La Constancia no por motivos económicos, ni, es obvio, por un arrebato futurista -aunque lo de tener acciones en un lugar en el que se fabrica la luz, la verdad, bonito y sorprendente sí que es-, sino porque creia, sinceramente, que cooperando con el progreso contribuía a que el mundo fuera mejor y la humanidad más feliz. Ubaldo Venier, el ingenuo accionista concienciado, conoció seguramente a Carmen de Burgos y entra dentro de lo probable que, a pesar del guantazo que ésta le había dado al orden sexual establecido "liándose" a plena luz del día con un jovenzuelo, le cayera bien. ¿Por qué no? Los dos fueron contemporáneos del regeneracionismo. $Y$ eso debe unir mucho.

Leopardi, en cambio, coincidió con Schopenhauer y Lord Byron. Es decir, vivió en un momento en el que, a pesar del sturm alemán y de sus transferencias al Risorgimento italiano, ser triste y pesimista había entrado a formar parte hasta del gusto amoroso. Es una simple curiosidad, pero no recuerdo ahora, en ningún texto anterior al Romanticismo, que alguien hable de la tristeza del amado/a como parte esencial de su atractivo. En la Provenza de finales del siglo XII, la condesa de Dia proclamaba, jubilosamente, que su amado era un hombre alegre y que, por eso mismo, ella vivía inundada de alegría. La Laura del Petrarca seducía por ese "lampeggiar" de su "angelico riso" que terminó desencadenando "relámpagos de risas carmesíes". Las maravillosas Rime de Gaspara Stampa dejan traslucir que su amado era un poco memo, además de inconstante, pero jamás un memo tristón. Según el catalogo de Leporello, a don Giovanni le gustaban gordas y flacas, altas y bajitas, pero no dice nada de las melancólicas. Y, sin embargo, una de las diversas mujeres que dejó constancia, por escrito, de lo fascinante que era Ugo Foscolo subraya que su incurable tristeza era uno de los motivos por los que era imposible no amarle. En otras palabras, cuando Lord Byron, según una célebre anécdota, protestó, al ver el retrato que acababan de hacerle, porque él tenía un aspecto mucho más infeliz, sabía lo que se decía. ¿Quién no ha protestado nunca porque en una foto ha salido más gorda o más vieja de lo que se considera? ¿Extraño? No sé. En un cuento, escrito por una mujer a mediados de los años 90, dos amigas hablan de un chico que le gusta a una de ellas: el joven es delgado, sensible, tiene siempre un aspecto muy triste $y_{\text {, ya }}$ puestas a agotar el tópico romántico, pinta, así, como de tuberculoso. Si a la condesa de Dia, no digamos a Leonor de Aquitania, les hubiesen dicho que a sus descendientes les iba a parecer atractivo un hombre porque, muy posiblemente, tiene destrozados los pulmones, no sé qué hubieran dicho. ¿Que, más que el amor, lo que anhelan es un puesto fijo en una ONG?

Bromas aparte, a partir del Romanticismo la tristeza se instaló en el gusto amoroso casi tanto como, en el deseo -las brame- de ser libres, el personaje del pirata (o sea, de esa curiosa fórmula de "mugre + delincuencia = libertad" por la que, lo confieso, yo también me estremecí cuando en Piratas del Caribe la protagonista precisa, mirando arrobada a su amado, que éste no es un honrado herrero, no: "Es un pirata"). Y eso, obviamente, es reflejo de algo. De esa filosofía, casi, del dolor, que elaboró el Romanticismo, por la que ser consciente del mismo llegó a adquirir una categoría heroica, y que fue uno de tantos legados románticos que yo aprehendí sin saber que lo eran. En mi adolescencia, por la misma época en que "La canción del pirata" de Espronceda había empezado a dejar de gustarme porque el libro Poemas y canciones de Bertolt Brecht se me abría solo por "La canción de Jenny", pero estaba ya a punto de adorar a Corto Maltese y al Bogart de $\mathrm{Ca}$ sablanca, que no dejan de ser los últimos grandes héroes byronianos, subrayé una frase de Novalis, creo, recogida por Herman Hesse: "Enorgullécete de tu dolor: es indicio de tu condición superior".

Casi como el pobre Leopardi, sí, en toda la línea de esa frase que le encantó a Carmen de Burgos: "Vive, [alma humana], y sé grande y sé infeliz". Pero tiene su sentido. En Los bandidos de Schiller se establecía la diferencia entre los individuos singulares, los que están llamados a vivir una existencia semejante al grandioso vuelo de las águilas, y el resto de la humanidad: los débiles, los mediocres, los que se conforman $y$, más que vivir, se dejan hacer por la vida (John Irving diría: "los que no consiguen ni ser los 
protagonistas de su propia historia". Con todo el afecto y la cercanía del mundo, eso sí. En el XX ya hemos aprendido a querernos también así). No era una idea nueva, claro. Que la vida le exige al ser humano algo más que nacer, reproducirse y morir, ese ciclo al alcance hasta de un vegetal, es algo que, creo recordar, ya se citaba como "verdad sabida" en La conjuración de Catilina y que, sin recurrir a citas, todos hemos manejado alguna que otra vez, para quejarnos, por ejemplo, de una vida laboral rutinaria y sin expectativa alguna ("no me han dado la vida para esto"), o para entender por qué a un amigo parece haberle alegrado más un ascenso que el nacimiento de su hijo. El deseo y la necesidad de destacar forman parte, me temo, del ADN cultural de todo ser humano.

La novedad del Romanticismo fue que esos seres singulares, para cumplir su grandeza, lo hacían enfrentados a la sociedad y las normas establecidas. Los héroes clásicos actúan desde la sociedad y, triunfando o fracasando, la consolidan -incluso Don Juan, el eterno y heroico trasgresor profesional; incluso la Juana-Gil y la villana de Vallecas de Tirso: sus enredos están encaminados a que sus respectivos amantes cumplan con su promesa de matrimonio, es decir, a que todo regrese al orden establecido-. Los románticos no. Los héroes románticos suelen ser proscritos -a Víctor Hugo le encantaba definirse así-, bandidos, corsarios, nobles expulsados de su propia corte. 0 jovencitos tan aquejados de spleen que, como Childe Harold y Eugenio Onieguin, no pueden amar porque no se creen el amor, es decir, no pueden acceder a uno de los elementos básicos que rigen su sociedad.

Y, si no puedes llevar hasta los últimos, heroicos, y rigurosamente solitarios extremos un amor, un ideal político, incluso un severo cuadro de spleen -si no puedes cumplir, hasta el final, con las exigencias de la vida-, antes de pactar con la mediocridad, lleva hasta el final su negación. Es decir, escribe, como Ugo Foscolo, un espléndido soneto en el que aseguras que siempre te gustó el atardecer porque es la imagen más perfecta de la muerte. 0 proyecta lo que más amas de ti mismo en personajes como Werther o Jacopo Ortis. Junto a Los bandidos, no se olvide, surgió inmediatamente el suicida como personaje esencial del Romanticismo.

¿Y Leopardi? Leopardi fue, hasta el final, el pajarillo solitario de uno de sus cantos más hermosos. Ser consciente de su dolor, extenderlo desde sí mismo a toda la condición humana y a la propia naturaleza, sin recurrir a engaños -que el año que viene va a ser estupendo; que Dios existe; que la humanidad puede feliz, sólo hace falta que haya luz eléctrica en todas las casas, que se redistribuya mejor la riqueza, que pueda rehacer legalmente mi vida amorosa después de plantar a un impresentable, que los señoritos se pongan también a trabajar- fue su grandeza romántica. Muy semejante a la que a mí me llegó, en la adolescencia, a través de un autor alemán que descubri por un disco de Carlos Santana, Abraxas.

En su última novela, Un sombrero lleno de cerezas, Oriana Fallaci desmitificaba de un zarpazo a Leopardi describiéndolo como "un literato jorobado, nacido en Recanati, que se pasaba el día tocando las pelotas a cuento de sus melancolías, su pésima salud, su escaso éxito con las mujeres, pero que era muy admirado por sus inspiradas poesías". Carmen de Burgos, obviamente, no sólo no lo desmitificó, sino que llegó, incluso, a creerse "demasiado" su dolor. Los hallazgos poéticos de Leopardi, su musicalidad, su perfecta inserción en la tradición poética italiana, le trajo, digamos, sin cuidado. La adolescente que cabalgaba por los campos de Rodalquilar, que llegaba hasta las playas más intensamente hermosas que yo he visto jamás, leyó, en definitiva, a Leopardi como una romántica desesperada. ¿Por qué? Que Unamuno, con su sentimiento trágico de la vida, se pasease por Canarias buscando retamas a las que presentarle sus respetos por el heroísmo con el que asumían que ya mismo iban a pisotearlas, lo entiendo de sobra. ¿Pero la optimista y valiente Colombine?

Una posible explicación me la dio, hace muchos años, mi profesor Domingo Induráin. Yo había insinuado, con toda la insolencia de mis veintipocos años, que lo poco que había leído del Romanticismo español me parecía como de cartón-piedra. Vamos, que Don Álvaro o La fuerza del sino y "La canción del pirata" eran a Los bandidos de Schiller, a Byron, Keats, Shelley y, por supuesto, a mis rendidas lecturas adolescentes de Foscolo y Leopardi, lo que un decorado de peplum al Partenón. La respuesta de Induráin me aclaró muchas cosas: cuando en España se adoptó, simplemente, el Romanticismo, aún no existían las condiciones sociales y económicas desde las que podría haber surgido con el ímpetu y la autenticidad con que lo hizo en Alemania, Inglaterra o el Norte de Italia. Por eso, nobles desdichados y piratas aparte, no se debatieron realmente

ARBOR CLXXXVI EXTRA JUNIO 2010 151-156 ISSN: 0210-1963 
los temas que estaban recorriendo el Romanticismo europeo. Esas condiciones se dieron luego: en la generación del 98. En Carmen de Burgos, como en Unamuno, un tardío y auténtico Romanticismo se solapó, pues, con las corrientes regeneracionistas de su época. Es, pensándolo bien, una idea que también explica mucho de Dostoievski y de los motivos por los que los personajes de Chejov, aunque trabajen, o sea, se regeneren, no logran mucho más que terminar siendo el Tío Vania o una jovencita que grita, algo inútilmente, que no quiere ser una gaviota a la que cualquiera puede disparar en cuanto se le antoje.

Leopardi, en su asilamiento de Recanati, no se planteó jamás, todo lo contrario, cómo combatir el dolor. Se planteó cómo expresarlo y cuál debía ser la postura de un romántico italiano "serio" ante el Ilamamiento de Madame de Staël. Carmen de Burgos, en Los inadaptados, recuerda cómo en el "paraíso perdido" de su infancia y adolescencia almerienses, "en aquellos tranquilos años de inocencia pasados en Rodalquilar, cuando en la ignorancia completa de la vida, sumergía la mirada en el azul de las aguas y los cielos" interrogaba "al más allá con la cándida fe de una soñadora inconsciente: [...] ¿Por qué existe el dolor?" Com- batirlo fue el motor de su vida y lo hizo con una seriedad y un compromiso ante los que incluso los coqueteos del propio Byron con la carboneria parecen una expresión más de spleen. Leer a Leopardi fue, quizá, su forma de entenderlo. Por eso, de una forma casi imperceptible, entendió tan bien qué amó éste en "su" Silvia: lo que ella no pareció dispuesta a dejar que muriera, jamás.

Porque Leopardi también escribió de ciertos momentos de la adolescencia en los que, pese a todo, existe una sensación indefinible en los que se presiente la certeza de la felicidad, y asimiló esa sensación a la figura de Teresa Fattorini, la criadita a la que llamó Silvia, una adolescente que aguardaba el inicio de la juventud "lieta e pensosa", "alegre y pensativa". Silvia murió en plena adolescencia, igual que se extinguieron en Leopardi aquellas sensaciones indefinibles, pero algo supo quedar de ellas. Lo que reconoció una almeriense comprometida y romántica fuera de tiempo que unió, pese a todo, en un hilo indefinible, su paraíso perdido de Rodalquilar con la felicidad que también se presintió en Recanati. Dos fragmentos, al final y pese a todo, de un mundo que insiste en ser inevitablemente amoroso.

Recibido: 14 de mayo de 2010

Aceptado: 7 de junio de 2010 